\title{
EL ARTÍCULO EN LA DINÁMICA DEL TEXTO LITERARIO
}

\author{
FRANCISCO CHICO RICO \\ (Universidad de Alicante)
}

디 propósito fundamental del presente estudio es doble. Por un lado, intentamos abordar el tratamiento lingüistico-textual y pragmático-lingüístico de la categoría tradicional del artículo en español. Por otro, nos atrevemos a contribuir de alguna manera a la mejor comprensión de las diferencias entre el discurso literario/poético y el no literario mediante la aplicación de los resultados de aquella reflexión a la canción V de Garcilaso de la Vega.

Evidentemente, debe ser en el nivel textual donde ha de llevarse a cabo la resolución más fiable y definitiva de cualquier problema lingüístico (Albaladejo-Garcia Berrio, 1982: 217-220) y, con mucho más motivo, cualquier ensayo definidor de las esencias caracterizadoras de la obra de arte verbal frente a las del discurso de lengua estándar (García Berrio, 1979), puesto que es el texto la unidad lingüística comunicativa esencial '. Esta corriente de investigación presupone, real y

1 Con respecto al texto como objeto lingüístico y a la textualidad como caracteristica fundamental de la comunicación lingüística, cfr., entre otros, Acosta, 1982: 15-30; Albaladejo, 1978, 1981, 1983; Albaladejo-García Berrio, 1982; Bernárdez, 1982: 15-100; Conte (a cura di), 1977; Coseriu, 1981; Daneś-Viehweger (Hrsg.), 1976; van Dijk, 1972, 1980, 1983a; van Dijk-Petöfi (eds.), 1977; Dressler, 1974; Dressler (ed.), 1978; Dressler (Hrsg.), 1978; García Berrio, 1978a, 1978b; Gülich-Raible, 1977; Hartmann, 1964, 1968, 1971, 1978, 1981; Jiménez Cano, 1983, 1984; Kallmeyer-Meyer Hermann, 1980; Petöfi, 1971, 1973, 1975, 1978a, 1978b, 1978c, 1978d, 1978e; Petöfi (ed.), 1979a, 1979b, 1981; Petöfi-García Berrio, 1978; Petöfi-Rieser, 1977; Petöfi-Rieser (eds.), 1973; Projektgruppe Textlinguistik Konstanz 
teóricamente, la consideración pragmática del objeto de estudio, es decir, su ampliación contextual dentro del ámbito comunicativo general -o ámbito textual (AT) - en el que un emisor (E), en un determinado contexto de producción (Cpr), transmite el texto $(T)$, elaborado según un plan macroestructural preestablecido, a un receptor $(R)$, en un contexto especifico de interpretación (Cin). $Y$ todo ello, en el mundo $\left(M_{1}\right) \circ$ mundos referenciales posibles $\left(M_{2}, M_{3}, \ldots M_{n}\right)$ (Albaladejo, 1986) de los que el texto y su contexto participan ${ }^{2}$. La figura I ejemplifica la situación de dichos componentes, donde las líneas discontinuas representan la relación empírica existente entre aquéllos dentro del AT en que se inser$\tan$ (Chico Rico, 1985):

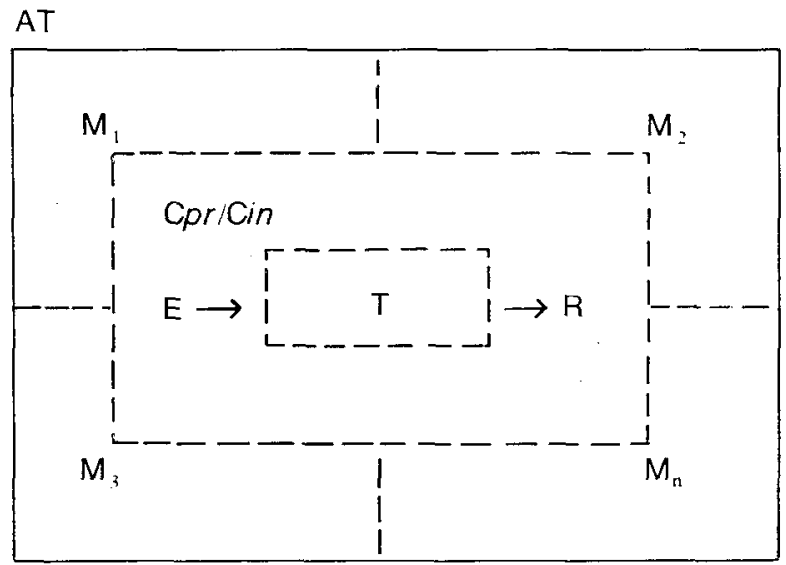

Figura 1

(Hrsg.), 1974; Rieser, 1978; Rosengren, 1980; Schmidt, 1977, 1978; Stempel (Hrsg.), 1971 y Tonfoni, 1981.

2 A propósito de las diferentes teorías pragmático-lingüisticas, cuya diversificación no impide en modo alguno la unificación de criterios en relación a su objeto de estudio, cfr. Albaladejo, 1983; Austin, 1962; Bar-Hillel (ed.), 1971; Breuer, 1974; Camps, 1976; Conte, 1983; van Dijk, 1972: 313 ss., 1976, 1980, 1983a; van Dijk (ed.), 1976; Ehrich-Finke (Hrsg.), 1975; Ferrara, 1976; Grunig, 1981; Guenthner-Schmidt (eds.), 1979; Gülich-Raible, 1977: 14-59; Jiménez Cano, 1983; Kummer, 1975, 1978; Levinson, 1983; Mey (ed.), 1979; Morris, 1972; Parret-Sbisa-Verschueren (eds.), 1981; Petöfi, 1975: 81-111, 1976; Ramón Trives, 1979: 169 ss., 1980; Sánchez de Zavala, 1972, 1973; Schlieben-Lange, 1980; Schmidt, 1973, 1977, 1978; Schmidt (Hrsg.), 1976; Schneider, 1975; Searle, 1979, 1980; Searle-Kiefer-Bierwisch (eds.), 1980; Wunderlich, 1972 y Wunderlich (Hrsg.), 1972. 
El componente pragmático es, en un marco teórico como el desarrollado por la TeSWeST " ampliada II (Albaladejo, 1983), el que gobierna en definitiva los procesos de producción y recepción del objeto fundamental comunicativo, en cuanto que la pragmática lingüísticotextual «tiene como objeto de estudio las relaciones que existen entre las expresiones de lengua natural, los participantes en el proceso comunicativo y el contexto de comunicación.» (Albaladejo, 1983: 4). Cualquier unidad comunicativa, perteneciente a cualquier sistema de modelización, según las propuestas de J. M. Lotman y, en general, de la Escuela de Tartu (Lotman, 1979: 41), constituye un texto, artístico o no, y representa un determinado modelo de mundo. Dicha representación, como entidad físicamente diferente y separable de la realidad extratextual modelizada, no tiene sentido al margen de ella y del sistema de valores y conocimientos del mundo presentes en cada uno de los comunicantes ni en el proceso de sintesis o producción (Petöfi, 1975: 1-33) ni en el de análisis o interpretación (Petöfi, 1975: 1-33). Esta mutua dependencia entre cotextualidad (Petöi, 1971: 224-225, 1975: 1) y contextualidad (Petöfi, 1971: 224-225, 1975: 1) es imprescindible en punto a la consecucion de una efectiva y correcta macroestructura textual, tanto en relacion a los intereses comunicativos del emisor como a la comprension exacta del mensaje por parte del receptor. Así pues, los diferentes componentes del AT anteriormente presentados contendrán, básicamente, en un nivel extensional, toda la información necesaria para la elaboracion, en un nivel intensional, de la macroestructura del texto:

El tratamiento del articulo desde esta perspectiva no ofrece considerable dificultad por su condicion de signo lingüistico metatextual, es decir. operativo en el nivel intensional o cotextual en tanto en cuanto

3 La TeSWeST (o teoria de la estructura del texto y de la estructura del mundo, del alemán "Textstruktur Weltstruktur Theorie») de János S. Petöfi constituye un completísimo modelo lingüistico-textual. Los trabajos que exponen la progresiva confección de tal teoría general del texto son los siguientes: Petöfi, 1973, 1975, 1978a, 1978b, 1978c y 1978d.

Por su parte, T. Albaladejo ha contribuido altamente al enriquecimiento del modelo general mediante la elaboración de importantes construcciones teóricas subyacentes a la realidad lingüistica comunicativa, como son el componente de representación (TeSWeST ampliada I) y el componente de pragmática textual (TeSWeST ampliada II), que constituye la parte general de la estructura de este modelo, desarrollados, respectivamente, en Albaladejo, 1981 y 1983.

4 Sobre la teoria de las macroestructuras textuales, cfr. Albaladejo, 1978: 362-365, 1984a; van Dijk, 1972, 1976, 1977, 1980, 1983a, 1983b: Garcia Berrio, 1978a: 57-61, 65-72 y Garcia Berrio-Albaladejo, 1983. 
constituye un signo lingüístico adnominal ("con función de referencia nominal» (Carbonero Cano, 1979: 25-26)), que, en general, como todas las expresiones deícticas o indexicales, remite a determinados componentes del AT, contribuyendo a la expresión de los tres modos bühlerianos de mostración (Bühler, 1979: 98-166), a saber, la demonstratio ad oculos, la deixis en phantasma - deíxis mostrativa contextual y deixis evocadora contextual respectivamente, puesto que orientan hacia determinados sectores de la realidad extralingüistica o del conocimiento enciclopédico del mundo propio de cada uno de los participantes en el proceso-, y la anáfora-catáfora -deixis fórica cotextual, en tanto que to hace hacia la estructura propiamente textual-manifestativa (Chico Rico, 1985)—. De ahí que el articulo, en un intento de ser redefinido desde planteamientos netamente estructural-funcionalistas (Vera Luján, 1979), forme parte de la subcategoría adjetivo-deíctica, basándonos en el contenido semántico exclusivamente endodeictico que lo informa (Chico Rico, 1985), ya que desempeña las funciones de complementación sémica nominal, no de un morfema, como casi siempre ha dicho la gramática estructural (Alarcos, 1978), sino de un adjetivo, como de alguna forma señaló una parte de la gramática tradicional (Seco, 1967).

El artículo, pues, analíticamente considerado, dirige la atención del receptor a una $u$ otra parte del texto $o$ al resto de las parcelas contextuales del AT (Weinrich, 1969, 1971). Concretamente, el artículo indeterminado remitirá al receptor, con vistas a la definición correcta del significado de su articulado (Weinrich, 1969: 212), a informaciones posteriores todavía no conocidas en relación a su aparición en el texto, actuando, por consiguiente, como elemento deíctico cotextual catafórico; por el contrario, el artículo determinado le orientará hacia informaciones anteriores, conocidas por él previamente a través de su conocimiento del texto interpretado hasta ese momento o del entorno contextual en el que aparece (Slama-Cazacu, 1970), comportándose como elemento deíctico cotextual anafórico o como elemento deíctico contextual mostrativo (demonstratio ad oculos) y evocador (deixis en phantasma).

Este estado de cosas facilita bastante la labor de sistematización de todas aquellas circunstancias que, en la dirección de sintesis textual, obligan al emisor a la utilización de un artículo $u$ otro. Ciertamente si se debe entender un articulado como determinado por una información posterior en el caso de que se halle antecedido por el artículo indeterminado, o bien por una información previa (co- o contextuai) si se encuentra indicado por el artículo determinado, es lógico pensar que los factores de «conocimiento" y udesconocimiento» de la información del articulado en cuestión, al menos por parte del receptor 
dentro de su AT, serán los que inciten al emisor, en situaciones normales de comunicación, al empleo de los artículos determinado e indeterminado respectivamente.

Una relación básica de circunstancias en las que la existencia de ciertos tipos de información cotextual y contextual comprometen la determinación articular en el texto al proporcionar la identificación exacta de la representación semántico-extensional de los respectivos articulados es la siguiente (Chico Rico, 1985):

\section{Circunstancias cotextuales.}

1.1. Situación de existencia de información cotextual previa.

1.2. Situación de existencia de información cotextual posterior.

\section{Circunstancias contextuales 5.}

2.1. Situación de existencia de información contextual física.

2.2. Situación de existencia de información contextual empirica.

2.3. Situación de existencia de información contextual natural.

2.4. Situación de existencia de información contextual práctica u ocasional.

2.5. Situación de existencia de información contextual histórica.

2.6. Situacion de existencia de información contextual cultural.

Por su parte, la utilizacion del artículo indeterminado, productivamente hablando, depende directamente, como siempre se ha dicho, del desconocimiento o imprevisión de la información de su articulado al menos por el receptor, esto es, de su ausencia como elemento paradigmático de las diferentes parcelas del AT hasta el momento de su aparición en el texto.

5 Las diferentes situaciones contextuales expuestas se corresponden integramente con los distintos tipos de contexto que en un importante estudio, y sin embargo largamente olvidado, destacó ya hace algunos años E. Coseriu (Coseriu, 1955-56: 315-317). Por tratarse de la más completa y sistematizada relación de contextos extraverbales que, desde un punto de vista especialmente comunicativo-textual, contribuyen a la determinación lingüistica y por sus amplias posibilidades de aplicación teórico-práctica, creo muy conveniente su utilización y potenciación. 
Debemos señalar, sin embargo, la relativa frecuencia de aparición de articulados precedidos por artículos definidos o indefinidos en situaciones obvias de inexistencia de información previa y de ausencia de información posterior en cada caso respectivo. Ello, según $\mathrm{H}$. Weinrich (Weinrich, 1969), se presenta siempre en un ámbito metalingüistico, en el sentido de que la información previa o posterior ausente debe ser suplida por las descripciones enciclopédicas propuestas por la competencia lingüística del receptor. Dichas descripciones, no obstante, no son idénticas para unos casos y otros, según el artículo precedido. Así, un sustantivo presentado en este cuadro teórico por el articulo determinado, ya singular, ya plural, debe ser entendido en su significación referencial más amplia y general, es decir, en su extensionalidad lógico-existencial o universal. Por el contrario, el significado del sustantivo acompañado por el indeterminado en el mismo cuadro depende, pura y simplemente, de la configuración sémica particular que, de acuerdo con el sistema de saberes y valores propios del receptor en un momento y lugar determinados, éste quiera hacer. De modo que, bien miradas, las categorias representadas por los conceptos de «información previa» e «información posterior» no dejan de ser constantes y operativas ni siquiera en el caso de la ausencia que comentamos, puesto que la intervención del conocimiento enciclopédico marcado por rasgos de cuantificación existencial para el primer caso y la importancia de la elaboración sémica «a posteriori» para el segundo no dejan de estar relacionadas con las citadas categorías.

Todo esto no hace más que desarrollar, desde puntos de vista más amplios, la doctrina de "lo consabido", estudiada muy acertadamente por el gramático Andrés Bello (Bello, 1982: 102) y colocada en su justo lugar por F. Lázaro Carreter (Lázaro, 1975), ya que aquélla explica indudablemente los procesos que inducen al hablante a elegir un artículo $u$ otro e incluso a prescindir de su presencia.

En efecto, la ausencia microestructural de artículo no siempre puede explicarse en términos de rasgos estilísticos de "esencialidad» (Alarcos, 1978; Alonso, 1973). Estudios más exhaustivos han demostrado que la repercusión fundamental de la falta de artículo sobre cualquier sustantivo supone no sólo un cierto grado de indeterminación, a veces esencial (Alarcos, 1978; Alonso, 1973), a veces cuantitativo-delimitativa (Sánchez de Zavala, 1976: 196 ss.), sino también un alto grado de determinación existencial (Lázaro, 1975) ${ }^{\circ}$.

6 F. Lázaro Carreter, en su trabajo titulado «El problema del artículo en español: una lanza por Bello», ya varias veces mencionado, es uno de los primeros en dudar de la 
Desde el punto de vista textual o, mejor, textual-comunicativo al que nos adscribimos y defendemos, y también desde una perspectiva estilística, el problema que tratamos podría entenderse mejor si atendiéramos a los criterios que más arriba nos servían para definir la naturaleza funcional de los artículos determinados e indeterminados. Realmente, si la presencia de artículo contribuye de manera diferente a la orientación del receptor en su proceso interpretativo dentro del AT, la ausencia de artículo lo que hace precisamente es prescindir de esas instrucciones de carácter atencional, propiciando sobremanera la creación de un sentimiento de relajación en el receptor e invitándole a idear por sí mismo su propia caracterización semántico-extensional del sustantivo implicado, a partir, claro está, de sus conocimientos léxicos. La similitud de comportamiento pragmático entre los casos de ausencia de artículo y de presencia de artículo indeterminado desprovisto de complementación informativa posterior, en este sentido, es total.

Algo parecido podría decirse con relación a todos aquellos casos en los que los artículos el y un pueden alternar sin modificar ostensibiemente el significado exacto de su articulado. Otra cuestión muy diferente consiste en determinar cuáles sean las condiciones requeridas para que dicha alternancia sea posible, cuestión de la que aquí no nos ocupamos. Pero, indudablemente, las motivaciones que inducen al emisor a elegir uno u otro creo que están basadas en las especificas

transcendencia de los efectos estilísticos derivados de la presencia y ausencia de artículo $(e / / \varnothing)$. En este sentido, escribe: «Antes de entrar a discutir si es lícito establecer la oposición el / $\varnothing$, debe señalarse que los efectos de significación existencial y esencial, anejos a ella según Amado Alonso, distan de ser constantes. He aquí casos de nombres presentados $\sin$ artículo, en los que no se percibe ninguna 'esencialidad':

[Eral don Paco un viejo chifladísimo, a quien hija y madre ponian en ridiculo. (J. Valera)

Vi que vaciaban los sacos sobre cubierta, extendiendo toda la arena hasta cubrir toda la superficie de los tablones. (B. Pérez Galdós)

El animal se prestaba a todo de buen grado, si bien el aprendizaje era prolijo y penoso, con lo cual, perro y amo ganaban... (R. Pérez de Ayala)

Los asientos estaban ocupados, y había público de pie en pasillos y estrado.

En todos estos ejemplos, y en muchos más que cualquiera podria aducir, el artículo resulta opcional, pero no es fácil admitir que su ausencia o su presencia produzcan los efectos semánticos descritos por A. Alonso. Ello significa que la regla por él propuesta - pues de una regla descriptiva se trata- deja muchos residuos cuando se contrasta con un corpus más amplio de oraciones; su poder parece, por tanto, escaso o nulo. Ante ejemplos como el cervantino "Yo sali de mi tierra, y dejé hijos y mujer por venir a servir a vuestra merced", en el que Alonso ve nitidamente ejemplificado el principio de la 'esencialidad', cabe, pues, sentir escepticismo, y preguntarse si ese efecto no deberá explicarse desde otros supuestos..." (Lázaro, 1975: 352-353). 
Intenciones estilístico-pragmáticas que estamos estudiando. F. Lázaro Carreter (Lázaro, 1975: 348) aduce que la misma Academia se da cuenta de que en ciertos contextos tan determinante es el como un, en ejemplos como:

1. [1.1] Un hombre cauto no acomete empresas superiores a sus fuerzas.

11.2] El hombre cauto no acomete empresas superiores a sus fuerzas.

2. [2.1] Juana canta como un ruiseñor.

|2.2| Juana canta como e/ ruiseñor.

Las diferencias, tanto en 1 como en 2 , no parecen, verdaderamente, radicar en la referencialidad de los respectivos sustantivos, sino, sobre todo, en la diversidad de estímulos orientativos que en el proceso analítico detecta el receptor. Mientras que $[1.1]$ y $[2.1]$ crean en nosotros expectativas de atención intensas en torno a la composición sémica completa y correcta - no lograda todavia hasta el momento de su recepción— de uno y otro articulado, los ejemplos [1.2| y |2.2| nos remiten directamente a conocimientos sobre dichos articulados supuestamente ya adquiridos cotextual o contextualmente, estando exentos, por tanto, de intereses informativos relevantes.

En nuestro proceso de interpretación, como receptores lingüistas (Albaladejo, 1981: 120) que somos, nos encontramos con la siguiente manifestación textual lineal de la canción $V$ de Garcilaso de la Vega, más conocida como Ode ad Florem Gnidi'

1.

Si de mi baja lira

tanto pudiese el son que en un momento

aplacase la ira

del animoso viento

5 y la furia del mar y el movimiento,

2.

y en ásperas montañas

con el süave canto enterneciese

las fieras alimañas,

los árboles moviese

7 En Garcilaso de la Vega, Poesias castellanas completas, edición, introducción y notas de Elías L. Rivers, Madrid, Castalia, 1972, pp. 93-98. 
10 y al son confusamente los trujiese:

3.

no pienses que cantado

seria de mí, hermosa flor de Gnido,

el fiero Marte airado,

a muerte convertido,

15 de polvo y sangre y de sudor teñido,

4.

ni aquellos capitanes

en las sublimes ruedas colocados,

por quien los alemanes,

el fiero cuello atados,

20 y los franceses van domesticados;

5.

mas solamente aquella

fuerza de tu beldad seria cantada,

y alguna vez con ella

también seria notada

25 el aspereza de que estás armada,

6.

y como por ti sola

$y$ por tu gran valor y hermosura, convertido en viola,

llora su desventura

30 el miserable amante en tu figura.

7.

Hablo d'aquel cativo

de quien tener se debe más cuidado,

que 'stá muriendo vivo,

al remo condenado,

35 en la concha de Venus amarrado.

8.

Por ti, como solía,

del áspero caballo no corrige

la furia y gallardía,

ni con treno la rige, 
9.

por ti con diestra mano

no revuelve la espada presurosa,

$y$ en el dudoso llano

huye la polvorosa

45 palestra como sierpe ponzoñosa;

10.

por ti su blanda musa,

en lugar de la cítera sonante.

tristes querellas usa

que con llanto abundante

50 hacen bañar el rostro del amante;

11.

por ti el mayor amigo

l'es importuno, grave y enojoso:

yo puedo ser testigo,

que ya del peligroso

55 naufragio fui su puerto y su reposo,

12.

y agora en tal manera

vence el dolor a la razón perdida

que ponzoñosa fiera

nunca fue aborrecida

60 tanto como yo dél, ni tan temida.

13.

No fuiste tú engendrada

ni producida de la dura tierra;

no debe ser notada

que ingratamente yerra

65 quien todo el otro error de sí destierra.

14.

Hágate temerosa

el caso de Anajárete, y cobarde,

que de ser desdeñosa

se arrepentió muy tarde, 
70 y así su alma con su mármol arde.

15.

Estábase alegrando

del mal ajeno el pecho empedernido

cuando, abajo mirando,

el cuerpo muerto vido

75 del miserable amante allí tendido,

16.

y al cuello el lazo atado

con que desenlazó de la cadena

el corazón cuitado,

y con su breve pena

80 compró la eterna punición ajena.

17.

Sentió alli convertirse

en piedad amorosa el aspereza.

¡Oh tarde arrepentirse!

¡Oh ultima terneza!

85 ¿Cómo te sucedio mayor dureza?

18.

Los ojos s'enclavaron

en el tendido cuerpo que alli vieron;

los huesos se tornaron

más duros y crecieron

90 y en sí toda la carne convertieron;

19.

las entrañas heladas

tornaron poco a poco en piedra dura;

por las venas cuitadas

la sangre su figura

95 iba desconociendo y su natura,

20.

hasta que finalmente,

en duro mármol vuelta y transformada,

hizo de si la gente

no tan maravillada 
100 cuanto de aquella ingratitud vengada.

21.

No quieras tú, señora, de Némesis airada las saetas probar, por Dios, agora; baste que tus perfetas

105 obras y hermosura a los poetas

22.

den inmortal materia,

sin que también en verso lamentable

celebren la miseria

d'algún caso notable

110 que por ti pase, triste, miserable.

El presente texto, en relación con el tema que nos interesa, contiene una desproporción enorme entre el número de ocurrencias de las formas determinadas del artículo y el de las formas indeterminadas. Concretamente, junto a cincuenta y cinco artículos determinados, solo aparece un indeterminado al comienzo del poema (v. 2). La supremacía cuantitativa del primero frente al segundo en cualquier discurso de lengua castellana es relativamente normal si nos fijamos en algunos estudios de tipo estadístico, como el llevado a cabo por R. Lapesa (Lapesa, 1976), donde se descubre que el uso del artículo determinado es considerablemente mayor que el del indeterminado en los textos literarios/poéticos y que el empleo del indeterminado aumenta, aunque en proporciones menores, en los textos de lengua estándar, en detrimento del número total de artículos determinados. Dicha desproporción en la oda horaciana de Garcilaso, y haciendo abstracción completa de todo el resto de rasgos constructores de ese gran complejo artístico, nos conduce directamente a su indudable consideración poética.

En el nivel macroestructural, según la organización de la TeSWeST, el artículo forma parte de los indices de referencia (García Berrio, 1978a: 85-87; Petöfi, 1973: 239), en tanto en cuanto constituye una categoría mostrativo-deíctica, y pertenece al bloque de elementos potenciales nucleares de la representación semántico-intensional del texto (Chico Rico, 1985).

Desarrollamos a continuación la lista de indices de referencia, representando canónicamente una muy amplia selección de sólo aquellas entradas léxicas que en la microestructura quedan presentadas por un 
artículo $u$ otro o por su ausencia, con el fin primordial de poder construir más tarde una posible red comunicativa (Garcia Berrio, 1978a: 85-87; Petöfi, 1973: 241) en la que se demuestre gráficamente el carácter temático del texto lírico.

\section{Lista de indices de referencia ${ }^{8}$}

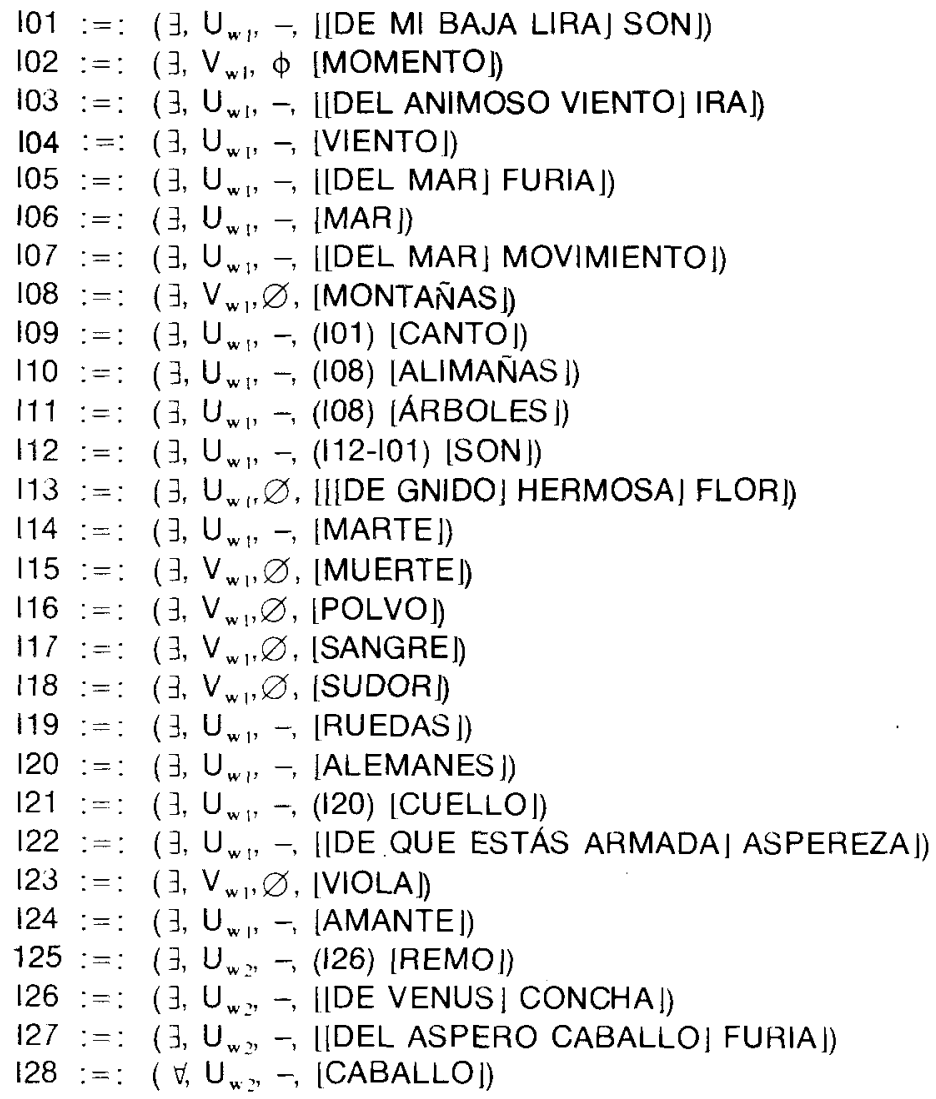

8 La representación canónica de la lista consta, fundamentalmente, de los siguientes elementos: a) 1 (índice de referencia); b) :=: (marca de reescritura); c) $\forall, \exists$ (cuantificadores universal y particular respectivamente); d) $U_{w n}, V_{w n}$ (identificador definidor e indefinidor $f)-, \varnothing, \phi$ (indicadores de información mínima, media y máxima respectivamente); g) (entrada léxica afectada). 


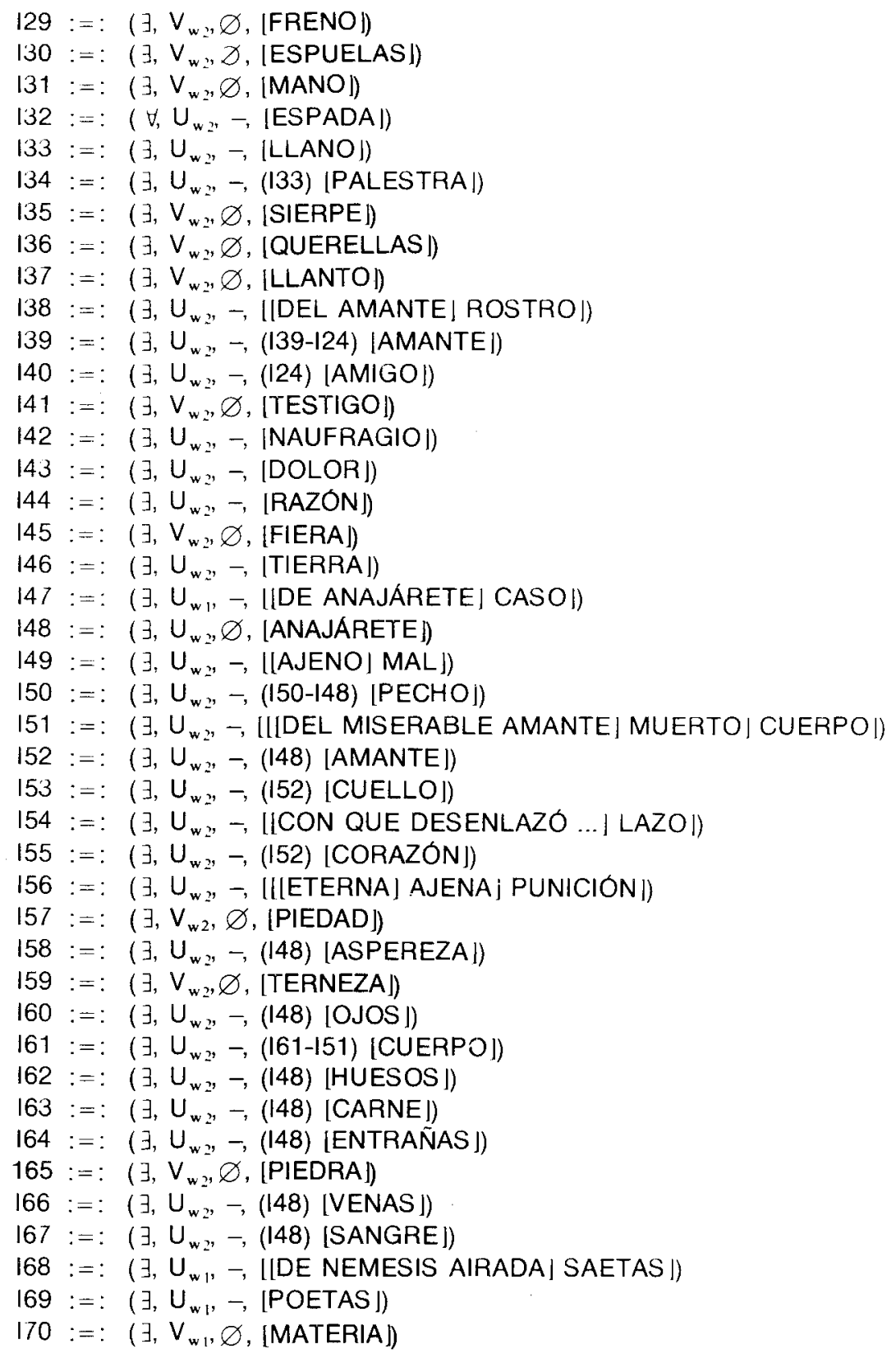




\section{$171:=:\left(\exists, \mathrm{V}_{\mathrm{w}_{1}}, \varnothing,[\mathrm{VERSO}]\right)$ \\ $172:=:\left(\exists, U_{w 1},-,[\right.$ [D'ALGÚN CASO NOTABLE] MISERIA])}

De los índices considerados, setenta y dos en total, solamente uno es indeterminado mediante artículo (102). Existe, sin embargo, un nutrido número de indices no presentados microestructuralmente por ningún tipo de artículo, algunos de los cuales son entendidos como definidos (148), frente al resto, que lo son como indeterminados esencial o cuantitativamente $(108,115,116,117,118,123,129,130,131,135,136$, $137,141,145,157,159,165,170,171)$. Y los determinados lo son, como ya sabemos, por cotextuación previa, en cuyo caso los índices implicados poseen una información adyacente compuesta por dos números, el suyo propio y aquel que constituye la primera mención de su articulado $(112,139,150,161)$; por cotextuación posterior, con estructura léxica compuesta o múltiple (101, 103, 105, 107, 113, 122, 126, 127, 138, 147, 149, 151, $154,156,168,172)$; cuando un índice especifica entre paréntesis como información suplementaria un único número, éste corresponde a aquel cuya entrada léxica le sirve de dominio epistémico o marco y la determinación se realiza gracias a la contextuación empírica (109, 110, 111, $121,125,134,140,152,153,155,158,160,162,163,164,166,167)$; o, en el resto de casos, por las contextuaciones física, natural, práctica u ocasional, historica y cultural $(104,106,114,119,120,124,133,142,143,144,146,169)$. La determinación logico-existencial o universal, producida por la presencia del articulo determinado en un cuadro de ausencias de informaclones definitorıas, es también patente en algunos momentos $(128,132)$.

\section{Red comunicativa}

Una red comunicativa, ampliamente entendida, es una representacion de todos aquellos elementos influyentes en la comunicación textual. Sin embargo, por nuestra parte, considerando el gran desvio temático que la elaboración de una red de este tipo supondría, nos limitaremos a plasmar gráficamente el modo comunicativo del artículo, con el fin de acceder a la clase de estructura comunicativa a él debida en nuestro texto objeto.

Resulta evidente, segun se desprende de la exposicion, que el carácter informativo del artículo determinado e indeterminado y de su ausencia es diferente. En términos generales, el articulo determinado introduce información conocida, implícita en uno $u$ otro componente del AT, mientras que el indeterminado provee informaciones totalmente nuevas, no previstas en dicho AT. Desde un punto de vista dinámico- 
comunicativo, el artículo determinado es introductor de información temática y el indeterminado lo es de información remática. La alternancia y sucesividad de uno y otro proporcionará, lógicamente, al texto, la imprescindible dinamicidad de que siempre consta en situaciones de viabilidad ${ }^{4}$.

Junto a ello, puesto que la ausencia articular no se halla necesariamente sujeta ni a posibles influencias informativas previas ni tampoco a cualquier tipo de amplificacion posterior, es decir, exime al sustantivo afectado de las tensiones deícticas ya estudiadas, suscitando en el receptor una descodificación sémica del mismo pragmática y desautomatizada "1", pues ésta dependeria ante todo de sus particulares conocimientos léxico-enciclopédicos, del tiempo y del lugar en el que la recepción se lleva a cabo -con lo que uno y otro presuponen en relación al estado físico y psíquico del receptor-y, en definitiva, de todos aquellos factores extralingǘísticos más amplios que determinan la comunicación -entendidos conjuntamente como «komplexe Voraussetzungssituation" o situación compleja de suposición, según las teorías comunicativas de S. J. Schmidt (Schmidt, 1978)-, podriamos argüir su condición informativa media, en tanto que aquel articulado ni sería completamente consabido ni actuaría como elemento aperturista de todo un horizonte de expectativas de información futura cotextual acerca de sí mismo.

Tales características, representadas en la lista de indices de referencia mediante los signos -,$\varnothing$ y $\phi$ (indicadores de información mínima o temática, media y máxima o remática, respectivamente), puede conducirnos a la estructura de la información, cualitativamente considerada, en la oda de Garcilaso, formalizada gráficamente en la figura II.

Como podemos observar, se trata de una estructura especiaimente temática, en la que predomina con mucho el nivel de la baja informatividad sobre la media, a la que podríamos calificar de psicológica, y, especialmente, sobre la máxima, cuya operatividad, desde esta perspectiva, estableceria las bases fundamentales generadoras del desarro-

9 A pesar de tratarse de una dualidad teórica especialmente surgida y desarrollada en el ámbito teórico oracional, la lingüística textual ha adoptado esta distinción como altamente fructífera en su análisis y la bibliografía en este sentido comienza a ser voluminosa. Cfr. a este propósito Dahl (ed.), 1974; Daneš, 1976; Dijk, 1980: 178 ss., 1983a: 150 ss.; Dressler, 1974: 77-82; García Berrio, 1978a: 63; Gülich-Raible, 1977: 60-89; Palková-Palek, 1978 y Petöfi, 1975: 35-80.

10 Sobre la noción de desautomatización, surgida en el seno de las investigaciones del formalismo ruso, que caracterizaría la lengua artística en relación a la estándar, cfr., entre otros, Albaladejo, 1984b: 151-160; Garcia Berrio, 1973: 111 ss., 1979: 148; Mukařovský, 1977; Pozuelo, 1980 y 1983: $19-38$. 


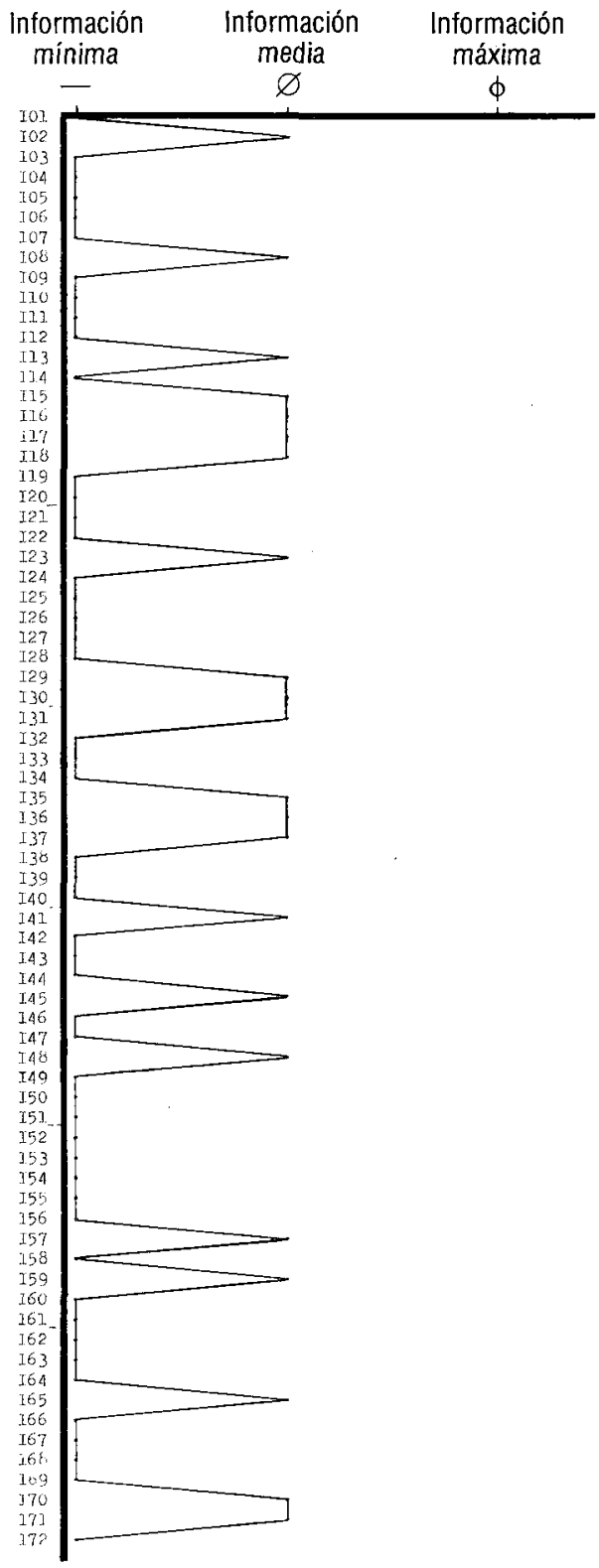

Figura II 
Ilo y la progresión temáticos textuales. El único artículo indeterminado del texto está exento de su eficacia remática al funcionar de la misma forma que la ausencia articular, según dijimos más arriba, debido a su comportamiento no fórico.

Así pues, lo que Garcilaso ha conseguido, ante todo, es una alta concentración de conceptos fácilmente comprensibles por quien recibe el texto. No olvidemos que ésta es una de las pocas composiciones del gran poeta castellano en la que su importante lirismo interior y subjetivo (que vendria dado en términos de supremacía general de sustantivos sin artículo) y su profunda fuerza psicológica (que lo haría en una especial utilización de los artículos determinados e indeterminados) es sustituido por una situación, por encima de todo, objetiva, vista desde fuera, puesto que no habla por él, sino por un amigo, Mario Galeota, a una dama, doña Violante Sanseverino, con intenciones muy especificas.

No queremos decir con ello que dicha estructura o estructuras parecidas contribuyan definitivamente a caracterizar lo literario/poético o, más concretamente, lo lírico, frente a otros tipos de discurso, pero está claro que constituyen «sintomas privilegiados y corrientes de insistencia que, sin dejar de ser genéricamente mecanismos existentes en el sistema general de "lengua», es indiscutible que constituyen sintomas $o$ indicios de un entendimiento especial de la lengua, al que se suele llamar literario o poético.» (García Berrio, 1979: 126). Y, definitivamente, sí parece que un escaso nivel informativo, dependiente de una mínima alternancia articular temático-remática, y, por consiguiente, una amplia dependencia del contexto, latamente entendido, provocan un efecto psicológico retardatorio, estático y atemporal, tendente, entre otras cosas, a la ambiguedad y al polisentido (Greimas, 1973; Ramón Trives, 1981), que caracterizan una gran parte de la producción artística. No en balde A. J. Greimas fundamentó la especificidad de la lengua literaria en hechos de progresivo agotamiento informativo a lo largo del discurso (Greimas, 1973: 318). «Tal fenómeno general -explica Greimas - queda sistematizado en la clausura del discurso. Gracias a ésta, que ya tiene la virtualidad de contener la avalancha de las informaciones, la redundancia cobra una nueva significación y, en vez de constituir una pérdida de información, valoriza los contenidos seleccionados y clausurados. La clausura transforma asi el discurso en objeto estructural y la historia en permanencia.» (Greimas, 1973: 318). 


\section{Referencias bibliográficas}

Abad, F., García Berrio, A. (coord.) (1982), Introducción a la lingüistica, Madrid, Alhambra.

Acosta, L. (1982), Cuestiones de lingüistica textual con una selección bibliográfica, Salamanca, Ediciones Universidad de Salamanca (Theses et Studia Philologica Salmanticensia, XXI).

Alarcos Llorach, E. (1978), “El artículo en español», en Estudios de gramática funcional del español, Madrid, Gredos, 1978, pp. 166177.

Albaladejo, T. (1978), "Considerazioni sulla teoria linguistica testuale», en Studi italiani di linguistica teorica ed applicata, VII, 3, Liviana editrice in Padova, pp. 359-382.

- (1981), "Aspectos del análisis formal de textos», en Revista española de lingüistica, XI, 1, pp. 117-160.

- (1983), «Componente pragmático, componente de representación y modelo lingüístico-textual», en Lingua e Stile, XVIII, 1, pp. 3-46.

- (1984a), «Estructura de sentido, representación textual semántico-intensional y tópico textual», en Anales de la Universidad de Murcia. Letras, XLIII, 1-2, curso 1984-85, pp. 265-284.

- (1984b), "La crítica lingüística», en Aullón de Haro, P. (coord.) (1984), pp. 141-207.

- (1986), Teoria de los mundos posibles y macroestructura narrativa. Análisis de las novelas cortas de Clarín, Alicante, Universidad de Alicante.

Albaladejo, T., García Berrio, A. (1982), "La lingüística del texto», en Abad, F., Garcia Berrio, A. (coord.) (1982), pp. 217-260.

Alonso, A. (1973), «Estilistica y gramática del artículo en español», en Estudios lingüisticos. Temas españoles, Madrid, Gredos, 1973, pp. $125-160$.

Althaus, H. P., Henne, H., Wiegand, H. E. (Hrsg.) (1973), Lexikon der germanistischen Linguistik, Tübingen, Max Niemeyer Verlag.

- (1980), Lexikon der germanistischen Linguistik, 2, vollständig neubearbeitete und erweiterte Auflage, Tübingen, Max Niemeyer Verlag.

Aulión de Haro, P. (coord.) (1984), Introducción a la crítica literaria actual, Madrid, Playor.

Austin, J. L. (1962), How to do things with words, Oxford, Oxford University Press.

Bar-Hillel, Y. (ed.) (1971), Pragmatics of natural languages, Dordrecht: Holland, D. Reidel Publishing Company (Synthese Library, 41). 
Bello, A. (1982), Gramática de la lengua castellana, Madrid, Edaf.

Bernárdez, E. (1982), Introducción a la lingüistica del texto, Madrid, Espasa-Calpe.

Breuer, D. (1974), Einführung in die pragmatische Textheorie, München, Wilhelm Fink Verlag (Uni-Taschenbücher, 106).

Bühler, K. (1979), Teoria del lenguaje, Madrid, Alianza Editorial.

Camps, V. (1976), Pragmática del lenguaje y filosofia analítica, BarceIona, Península (Historia, Ciencia, Sociedad, 129).

Carbonero Cano, P. (1979), Deíxis espacial y temporal en el sistema lingüistico, Sevilla, Servicio de Publicaciones de la Universidad de Sevilla.

Conte, M. E. (a cura di) (1977), La linguistica testuale, Milano, Feltrinelli.

- (1983), «La pragmatica linguistica», en Segre, C. (a cura di) (1983), pp. 94-128.

Coseriu, E. (1955-1956), «Determinación y entorno», en Coseriu, E. (1973), pp. 282-323.

- (1973), Teoria del lenguaje y lingüistica general, Madrid, Gredos.

- (1981), Textlinguistik. Eine Einführung, Tübingen, Gunter Narr Verlag (Tübinger Beiträge zur Linguistik, 109).

Chico Rico, F. (1985), «Sobre el artículo español y su comportamiento en el ámbito textual. A propósito de un cuento de $\mathrm{E}$. Pardo Bazán», en Analecta Malacitana (en prensa).

Dahl, O (ed.) (1974), Topic and comment, contextual boundness and focus, Hamburg, Helmut Buske Verlag (Papiere zur Textlinguistik, $6)$.

Danes, F. (1976), «Zur semantischen und thematischen Struktur des Kommunikats", en Danes, F., Viehweger, D. (Hrsg.) (1976), pp. 29-40.

Daneš, F., Viehweger, D. (Hrsg.) (1976), Probleme der Textgrammatik, Berlin, Akademie-Verlag (Studia Grammatica, XI).

Dijk, T. A. van (1972), Some Aspects of Text Grammars. A Study in Theoretical Linguistics and Poetics, The Hague-Paris, Mouton.

- (1976), Per una Poetica generativa, Bologna, II Mulino.

- (1977), «Nota sulle macrostrutture linguistiche», en Conte, M. E. (a cura di) (1977), pp. 181-194.

- (1980), Texto y Contexto. Semántica y Pragmática del discurso, Madrid, Cátedra.

- (1983a), La ciencia del texto. Un enfoque interdisciplinario, Barcelona, Paidós (Comunicación, 5).

- (1983b), Estructuras y funciones del discurso. Una introducción interdisciplinaria a la lingüistica del texto y a los estudios del discurso, México, Siglo XXI. 
Dijk, T. A. van (ed.) (1976), Pragmatics of Language and Literature, vol. 2, Amsterdam, North-Holland Publishing Company.

Dijk, T. A. van, Petöfi, J. S. (eds.) (1977), Grammars and Descriptions. Studies in Text Theory and Text Analysis, Berlin-New York, Walter de Gruyter.

Dressler, W. U. (1974), Introduzione alla linguistica del testo, Roma, Officina.

- (ed.) (1978), Current Trends in Textlinguistics, Berlin-New York, Walter de Gruyter.

- (Hrsg.) (1978), Textlinguistik, Darmstadt, Wissenschaftliche Buchgeselischaft.

Ehrich, V., Finke, P. (Hrsg.) (1975), Beiträge zur Grammatik und Pragmatik, Kronberg/Ts., Scriptor Verlag GmbH \& Co. (Skripten Linguistik und Kommunikationswissenschaft, 12).

Ferrara, A. (1976), Grammatica del testo: Semantica e Pragmatica, Palermo, Quaderni del Circolo Semiologico Siciliano, 7.

García Berrio, A. (1973), Significado actual del formalismo ruso. (La doctrina de la escuela del método formal ante la poética y la lingüistica modernas), Barcelona, Planeta.

- (1978a), «Situación de la teoría textual. (La teoría de J. S. Petöfi en el marco de la lingüística del texto)", en Petöfi, J. S., García Berrio, A. (1978), pp. 53-98.

- (1978b), «Texto y oración. Perspectivas de la lingüistica textual», en Petöfi, J. S., García Berrio, A. (1978), pp. 243-264.

- (1979), «Lingüística, literaridad/poeticidad (Gramática, Pragmática, Texto)», en 1616. Anuario de la Sociedad Española de Literatura General y Comparada, II, pp. 125-170.

García Berrio, A., Albaladejo, T. (1983), «Estructura composicional. Macroestructuras", en Estudios de Lingüistica. Universidad de Alicante, 1, pp. 127-180.

Gracia, F. (comp.) (1972), Presentación del lenguaje, Madrid, Taurus.

Greimas, A. J. (1973), En torno al sentido. Ensayos semióticos, Madrid, Fragua.

Grunig, B. N. (1981), «Plusieurs pragmatiques», en D.R.L.A.V. Revue de linguistique, 25, pp. 101-118.

Guenthner, F., Schmidt, S. J. (eds.) (1979), Formal Semantics and Pragmatics for Natural Languages, Dordrecht: Holland, D. Reidel Publishing Company (Synthese Language Library, 4).

Gülich, E., Raible, W. (1977), Linguistische Textmodelle. Grundlagen und Möglichkeiten, München, Wilhelm Fink Veriag (Uni-Taschenbücher, 130). 
Hartmann, P. (1964), «Text, Texte, Klassen von Texten», en Bogawus, 2, pp. $15-25$.

- (1968), «Zur Aufgabe der Textlinguistik», en Lingua, 21, pp. 197215.

- (1971), «Texte als linguistisches Objekt», en Stempel, W. D. (Hrsg.) (1971), pp. 9-29.

- (1978), «Textlinguistik als linguistische Aufgabe», en Dressier, W. U. (Hrsg.) (1978), pp. 93-105.

- (1981), «Text und Satz», en Petöfi, J. S. (ed.) (1981), pp. 112-126.

Jiménez Cano, J. M. (1983), «Problemática metodológica en el análisis de los fenómenos textuales y pragmáticos", en Anales de la Universidad de Murcia, XLI, 1-2, Facultad de Letras, curso 1982-83, pp. 299-370.

- (1984), «Producción lingüística, usuario lingüístico y teoria del texto", en Anales de la Universidad de Murcia. Letras, XLIII, 1-2, curso 1984-85, pp. 127-171.

Kallmeyer, W., Meyer Hermann, R. (1980), «Textlinguistik», en Althaus, H. P., Henne, H., Wiegand, H. E. (Hrsg.) (1980), pp. 242-258.

Kummer, W. (1975), Grundlagen der Texttheorie. Zur handlungstheoretischen Begründung einer materialistischen Sprachwissenchaft, Hamburg, Rowohlt (Linguistik, 51).

- (1978), «Referenz, Pragmatik und zwei mögliche Textmodelle», en Dressier, W. U. (Hrsg.) (1978), pp. 328-343.

Lapesa, R. (1976), «Dos estudios sobre la actualización del sustantivo en español», en Boletin de la Comisión Permanente de las Reales Academias, pp. 39-67.

Lázaro Carreter, F. (1975), «El problema del artículo en español: una lanza por Bello", en Homenaje a Rodriguez Moñino, Madrid, pp. 347-371.

Levinson, S. C. (1983), Pragmatics, Cambridge, Cambridge University Press.

Lotman, J. M. (1979), «El probiema del sıgno y del sistema sígnico en la tipología de la cultura anterior al sigio $X X_{\text {» }}$, en Lotman, J. M. y Escuela de Tartu (1979), pp. 41-66.

Lotman, J. M. y Escuela de Tartu (1979), Semiótica de la cultura, Madrid, Cátedra.

Vey, J. L. (ed.) (1979), Pragmalınguistics. Theory and Practıce, The Hague, Mouton (Rasmus Rask Studies in Pragmatıc Linguistıcs, 1).

Vorrıs, CH. W. (1972), "Fundamentos de la teoría de los sıgnos", en ìracia, F. (comp.) (1972), pp. 53-65.

Mukařovský, J. (1977), «Lenguaje standard y lenguaje poétıco», en Escritos 
de estética y semiótica del arte, Barcelona, Gustavo Gili, 1977, pp. 314-333.

Palková, Z., Palek, B. (1978), «Functional Sentence Perspective and Textlinguistics», en Dressler, W. U. (ed.) (1978), pp. 212-227.

Parret, H., Sbisà, M., Verschueren, J. (eds.) (1981), Possibilities and limitations of Pragmatics. Proceedings of the Conference on Pragmatics. Urbino, July 8-14, 1979, Amsterdam, John Benjamins B. V. (S.L.C.S., 7).

Petofı, J. S. (1971), Transtormatıonsgrammatiken und eine ko-textuelle Texttheorie. Grundfragen und Konzeptionen, Frankfurt am Main, Athenaum Verlag (Linguistische Forschungen, 3).

- (1973), «Towards an Empirically Motivated Grammatical Theory of Verbal Texts", en Petöfi, J. S., Rieser, H. (eds.) (1973), pp. 205-275.

- (1975), Vers une théorie partielle du texte, Hamburg. Helmut Buske Verlag (Papiere zur Textlinguistik, 9).

- (1976), «Formal Pragmatics and a Partial Theory of Texts", en Schmidt, S. J. (Hrsg.) (1976), pp. 105-121.

- (1978a), "La teoria lógico-semántica de las lenguas naturales como teoría textual. (Programa de investigación para lingüistica formal y lógica natural)", en Petöfi, J. S., García Berrio, A. (1978), pp. 99-125.

- (1978b), «Una teoría textual formal y semiótica como teoría integrada del lenguaje natural. (Notas metodológicas)", en Petöfi, J. S., Garcia Berrio, A. (1978), pp. 127-145.

- (1978c), «Estructura y función del componente gramatical de la teoría de la estructura del texto y de la estructura del mundo", en Petöfi, J. S., Liarcía Berrio, A. (1978), pp. 147-189.

- (1978d), "Léxico, conocimiento enciclopédico, teoría del texto", en Petöfi, J. S., García Berrio, A. (1978), pp. 191-213.

- (1978e), «La representación del texto y el léxico como red semántica", en Petöfi, J. S., Garcia Berrio, A. (1978), pp. 215-242.

- (ed.) (1979a), Text vs Sentence. Basic Questions of Text Linguistics. First Part, Hamburg, Helmut Buske Verlag (Papiere zur Textiinguistik, 20-1).

- (ed.) (1979b), Text vs Sentence. Basic Questions of Text Linguistics. Second Part, Hamburg, Helmut Buske Verlag (Papiere zur Textlinguistik, 20-2).

- (ed.) (1981), Text vs Sentence. Continued, Hamburg, Helmut Buske Verlag (Papiere zur Textlinguistik, 29).

Petöfi, J. S., García Berrio, A. (1978), Lingüística del texto y crítica literaria, Madrid, Comunicación. 
Petöfi, J. S., Rieser, H. (1977), «Some Arguments against counter-revoIution. On Marcelo Dascal's and Avishai Margalit's «A New 'Revolution' in Linguistics'? - 'Text-Grammars' vs. 'Sentence-Grammars's», en Linguistics, 188, Mouton Publishers, pp. 11-22.

- (eds.) (1973), Studies in Text Grammar, Dordrecht: Holland, D. Reidel Publishing Company (Foundations of Language. Supplementary Series, 19).

Pozuelo Yvancos, J. M. (1980), «Lingüística y poética: desautomatizaclon y literariedad", en Anales de la Universidad de Murcia. Letras, XXXVII, 4, curso 1978-79, pp. 91-144

- (1983), La lengua literaria, Málaga, Ágora.

Projektgruppe Textlinguistik Konstanz (Hrsg.) (1974), Probleme und Perspektiven der neueren textgrammatischen Forschung 1, Hamburg. Helmut Buske Verlag (Papiere zur Textlinguistik, 5).

Ramon Trives, E. (1979), Aspectos de semántica lingüístico-textual, Madrid, Istmo-Alcalá.

- (1980), "Nuestro hablar: proceso pragmáticamente no exento", en Monteagudo, 68, Universidad de Murcia, pp. 13-20.

- (1981), "Aproximación metateorica a la producción literaria», en Tránsito. Revista de poesia, h-i, pp. 17-23.

Rieser, H. (1978), «Introducción. El desarrollo de la gramática textual», en Petöfi, J. S., García Berrio, A. (1978), pp. 19-50.

Rosengren, I. (1980), "Texttheorie", en Althaus, H. P., Henne, H., Wiegand, H. E. (Hrsg.) (1980), pp. 275-286.

sánchez de Zavala, V. (1972), «Perspectivas actuales de una praxiología lingüística», en Gracia, F. (comp.) (1972), pp. 333-375.

- (1973), Indagaciones praxiológicas. Sobre la actividad lingüistica, Madrid, Siglo XXI.

- (1976), "Sobre una ausencia del castellano», en Sánchez de Zavala, V. (coord.) (1976), pp. 195-254.

- (coord.) (1976), Estudios de gramática generativa, Barcelona, Labor Universitaria.

Schlieben-Lange, B. (1980), Linguistica pragmatica, Bologna, II Mulino. jchmidt, S. J. (1973), "Texttheorie/Pragmalinguistik», en Althaus, H. P., Henne, H., Wiegand, H. E. (Hrsg.) (1973), pp. 233-244.

- (1977), Teoría del texto. Problemas de una lingüística de la comunicación verbal, Madrid, Cátedra.

- (1978), "Some Problems of Communicative Text Theories", en Dressler, W. U. (ed.) (1978), pp. 47-60.

- (Hrsg.) (1976), Pragmatik/Pragmatics II. Zur Grundlegung einer expliziten Pragmatik, München, Wilhelm Fink Verlag. 
Schneider, H. J. (1975), Pragmatik als Basis von Semantik und Syntax, Frankfurt am Main, Suhrkamp.

Searle. J. R. (1979), Expression and Meaning. Studies in the theory of speech acts, Cambridge, Cambridge University Press.

- (1980), Actos de habla. Ensayo de filosofia del lenguaje, Madrid, Cátedra.

Searle, J. R., Kiefer, F., Bierwisch, M. (eds.) (1980), Speech Act Theory and Pragmatics, Dordrecht: Holland, D. Reidel Publishing Company (Synthese Language Library, 10).

Seco, R. (1967), Manual de gramática española, Madrid, Aguilar.

Segre, C. (a cura di) (1983), Intorno alla linguistica, Milano, Feltrinelli.

Slama-Cazacu, T. (1970), Lenguaje y contexto. El problema del lenguaje en la concepción de la expresión y de la interpretación por las organizaciones del contexto, Barcelona, Urijalbo.

Stempel, W. D. (Hrsg.) (1971), Beiträge zur Textlinguistik, München. Fink.

Tonfoni, ì. (1981), "Frase, discorso, testo», en Lingua e Stile, XVI, 3, pp. 371-392.

Vera Luján, A. (1979), “Los adjetivos deícticos en español», en Anales de la Universidad de Murcia. Letras, XXXVIII, 1. curso 1979-80, pp. $159-176$

Weinrich, H. (1969), "Linguística del texto: sobre la sintaxis del artículo en la lengua alemana», en Weinrich. H. (1981), pp. 203-222.

- (1971). "Sintaxis textual del artículo francés", en Weinrich. $H$. (1981). pp. 234-249.

- (1981). Lenguaje en textos, Madrid. Uiredos.

Wunderıch, D. (1971), «Pragmatıque. situatıon d'énoncration et deixis", en Langages. 26. pp. 34-58.

- (Hrsg.) (1972). Linguistische Pragmatik. Frankfurt am Main. Athenaum (schwerpunkte Linguistık und Kommunikationswissenschaft, 12) 